\title{
Isolation, Structural Assignment of Isoselagintamarlin A from Selaginella tamariscina and Its Biomimetic Synthesis
}

\author{
Qin-Feng Zhu ${ }^{1,2} \cdot$ Li-Dong Shao $^{1} \cdot$ Xing-De Wu ${ }^{1} \cdot$ Jiang-Xin Liu ${ }^{1} \cdot$ Qin-Shi Zhao ${ }^{1}$
}

Received: 6 November 2018 / Accepted: 3 December 2018 / Published online: 3 January 2019

(c) The Author(s) 2019

\begin{abstract}
Isoselagintamarlin A (1), a selaginellin analogue featured a rare benzofuran unit, was isolated from Selaginella tamariscina. Its complete structural assignment was established through a combination of high-field NMR technique and biomimetic synthesis. Notably, isoselagintamarlin A (1) was successfully synthesized via sequential oxidations and intramolecular cyclization.
\end{abstract}

\section{Graphical Abstract}

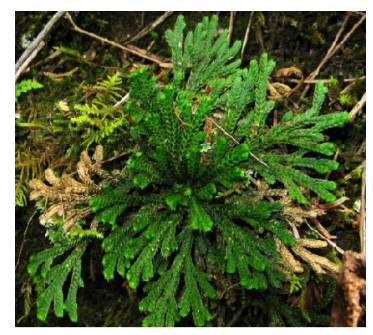

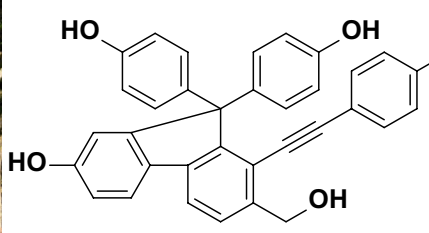

selaginpulvilin $\mathrm{A}$

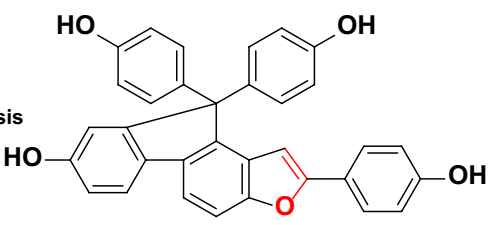

Isoselagintamarlin A

Keywords Selaginella tamariscina $\cdot$ Selaginellin $\cdot$ Biomimetic synthesis · Isoselagintamarlin A

\section{Introduction}

The selaginellin derivatives, isolated from the genus Selaginella, are a family of natural pigments characterized by acetylenic link and $p$-quinone methide functionalities [1-4]. The isolation and synthesis of selaginellin and its analogues have attracted tremendous attentions recently due to

Electronic supplementary material The online version of this article (https://doi.org/10.1007/s13659-018-0195-5) contains supplementary material, which is available to authorized users.

Qin-Shi Zhao

qinshizhao@mail.kib.ac.cn

1 State Key Laboratory of Phytochemistry and Plant Resources in West China, Kunming Institute of Botany, Chinese Academy of Sciences, Kunming 650201, People's Republic of China

2 University of Chinese Academy of Sciences, Beijing 100049 , People's Republic of China their fascinating structures and a wide range of biological activities [5-11]. Selaginella tamariscina, a qualified species listed in the Chinese Pharmacopoeia, has been used in Traditional Chinese Medicine for the treatment of amenorrhea, dysmenorrhea, and traumatic injury, and has been reported containing some selaginellin derivatives [12]. In an earlier study towards the discovery of structurally interesting and bioactive natural products, several selaginellin analogues with good inhibitory activities against BACE1 were previously reported from S. tamariscina [13]. In the current study, a further phytochemical investigation on this plant led to the isolation of an unprecedented benzofurantype selaginellin derivative named isoselagintamarlin A (1), along with four known analogues, selaginpulvilins A-D (25) (Fig. 1). Herein, we present the isolation and complete structural assignment of isoselagintamarlin A (1) based on the combination of high-field NMR techniques and the first biomimetic synthesis. 


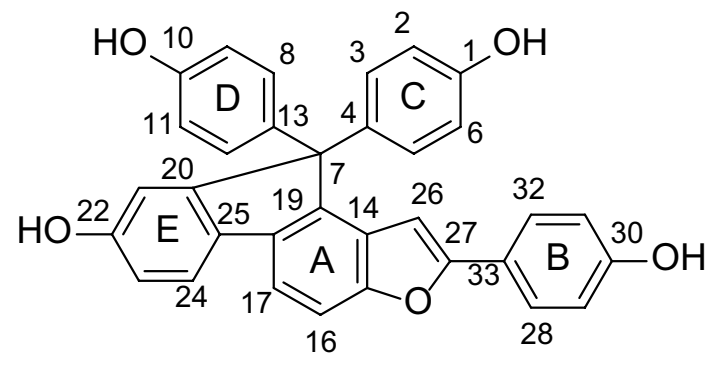

1

Fig. 1 Structures of compounds 1-5

\section{Results and Discussion}

The air-dried and powdered whole plants of S. tamariscina were extracted with $70 \% \mathrm{EtOH}$ for three times. Further column chromatography (CC) over MCI gel, normal-phase silica gel, Sephadex LH-20 and semi-preparative HPLC led to the isolation of one new selaginellin derivative (1), and four known ones (2-5).

Compound (1) was obtained as yellow oil. Its molecular formula was determined as $\mathrm{C}_{33} \mathrm{H}_{22} \mathrm{O}_{5}$ by HR-EI-MS with an ion peak at $m / z 498.1454[\mathrm{M}]^{+}$(calcd 498.1467), which indicated 23 degrees of unsaturation. The IR spectrum exhibited absorption bands for hydroxy $\left(3427 \mathrm{~cm}^{-1}\right)$ and aromatic $\left(1612\right.$ and $\left.1507 \mathrm{~cm}^{-1}\right)$ functionalities. Some aromatic proton signals at 6.80-7.00 ppm overlapped each other in the ${ }^{1} \mathrm{H}$ NMR spectrum obtained from a $600 \mathrm{MHz}$ spectrometer (Fig. S1, Electronic supplementary material). In order to characterize those key signals, the NMR experiments of compound 1 were carried out in an $800 \mathrm{MHz}$ spectrometer, and we were pleased to find that the overlapping proton signals were distinguishable (Fig. S2, Electronic supplementary material). The ${ }^{1} \mathrm{H}$ NMR spectrum of 1 (Table 1) showed the signals of three $p$-substituted phenyl groups (two were overlapped) $\left[\delta_{\mathrm{H}} 6.70(4 \mathrm{H}, \mathrm{d}\right.$, $J=8.9 \mathrm{~Hz}, \mathrm{H}-2,6,9,11), 7.08(4 \mathrm{H}, \mathrm{d}, J=8.9 \mathrm{~Hz}, \mathrm{H}-3$, $5,8,12), 6.90(2 \mathrm{H}, \mathrm{d}, J=8.8 \mathrm{~Hz}, \mathrm{H}-29,31), 7.72(2 \mathrm{H}, \mathrm{d}$, $J=8.8 \mathrm{~Hz}, \mathrm{H}-28,32)]$, a 1,2,4-trisubstituted benzene ring $\left[\delta_{\mathrm{H}} 6.83(1 \mathrm{H}, \mathrm{d}, J=8.1,2.3 \mathrm{~Hz}, \mathrm{H}-23), 6.91(1 \mathrm{H}, \mathrm{s}, \mathrm{H}-21)\right.$, $7.65(1 \mathrm{H}, \mathrm{d}, J=8.1 \mathrm{~Hz}, \mathrm{H}-24)]$, a 1,2,3,4-tetrasubstituted phenyl ring $\left[\delta_{\mathrm{H}} 7.49(1 \mathrm{H}, \mathrm{d}, J=8.3 \mathrm{~Hz}, \mathrm{H}-16), 7.66(1 \mathrm{H}\right.$, $\mathrm{d}, J=8.3 \mathrm{~Hz}, \mathrm{H}-17)]$, and an olefinic proton $\left[\delta_{\mathrm{H}} 6.88(1 \mathrm{H}\right.$, br s, H-26)]. The ${ }^{13} \mathrm{C}$ NMR data (Table 1 ) in combination with DEPT spectra exhibited 33 carbon signals that were ascribable to an alkenyl $\left(\delta_{\mathrm{C}} 157.5, \mathrm{C}-27 ; 99.0, \mathrm{C}-26\right)$, three $p$-phenyl groups (two were overlapped), two polysubstituted phenyl rings, and an $s p^{3}$ quaternary carbon $\left(\delta_{\mathrm{C}} 65.1\right.$, $\mathrm{C}-7)$. The aforementioned information was indicative of<smiles>[R]c1ccc(-c2ccc(O)cc2)c(C(c2ccc(O)cc2)(c2ccc(O)cc2)c2ccc(O)cc2)c1C#Cc1ccc(O)cc1</smiles>

$\begin{array}{ll}2 \mathrm{R}=\mathrm{CH}_{2} \mathrm{OH} & 3 \mathrm{R}=\mathrm{CHO} \\ 4 \mathrm{R}=\mathrm{CH}_{3} & 5 \mathrm{R}=\mathrm{H}\end{array}$

Table 1 NMR data of compound $\mathbf{1}(\delta$ in ppm, $J$ in $\mathrm{Hz}$ )

\begin{tabular}{|c|c|c|c|}
\hline Position & $\delta_{\mathrm{H}}^{\mathrm{a}}$ & $\delta_{\mathrm{C}}^{\mathrm{b}}$ & $\mathrm{HMBC} \mathrm{H} \rightarrow \mathrm{C}^{\mathrm{b}}$ \\
\hline $1 / 10$ & & 157.0 & \\
\hline $2 / 6 / 9 / 11$ & $6.70(\mathrm{~d}, J=8.9)$ & 115.7 & $1,3,4$ \\
\hline $3 / 5 / 8 / 12$ & $7.08(\mathrm{~d}, J=8.9)$ & 130.4 & $1,2,7$ \\
\hline $4 / 13$ & & 136.2 & \\
\hline 7 & & 65.1 & \\
\hline 14 & & 127.3 & \\
\hline 15 & & 155.3 & \\
\hline 16 & $7.49(\mathrm{~d}, J=8.3)$ & 110.8 & $14,15,18$ \\
\hline 17 & $7.66(\mathrm{~d}, J=8.3)$ & 115.8 & 19,25 \\
\hline 18 & & 135.8 & \\
\hline 19 & & 144.0 & \\
\hline 20 & & 156.0 & \\
\hline 21 & $6.91(\mathrm{~s})$ & 113.5 & $7,22,23,25$ \\
\hline 22 & & 157.8 & \\
\hline 23 & $6.83(\mathrm{dd}, J=8.1,2.3)$ & 115.3 & $21,22,25$ \\
\hline 24 & $7.65(\mathrm{~d}, J=8.1)$ & 121.0 & $18,20,22$ \\
\hline 25 & & 133.1 & \\
\hline 26 & 6.88 (br s) & 99.0 & $14,15,27$ \\
\hline 27 & & 157.5 & \\
\hline $28 / 32$ & $7.72(\mathrm{~d}, J=8.8)$ & 127.4 & $27,29,30$ \\
\hline $29 / 31$ & $6.90(\mathrm{~d}, J=8.8)$ & 116.6 & 30,33 \\
\hline 30 & & 159.2 & \\
\hline 33 & & 122.7 & \\
\hline
\end{tabular}

Assignments confirmed by DEPT, HSQC, HMBC, COSY, and ROESY NMR experiments

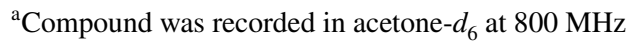

${ }^{\mathrm{b}}$ Compound was recorded in acetone- $d_{6}$ at $200 \mathrm{MHz}$

the skeleton of a selaginpulvilin derivative [7], with the structural variations occuring on the alkynyl and formyl parts.

The connectivities of these benzene rings, the quaternary carbon and the alkenyl could be well interpreted by 2D NMR analysis (Fig. 2). Two symmetrical para-substituted benzene 


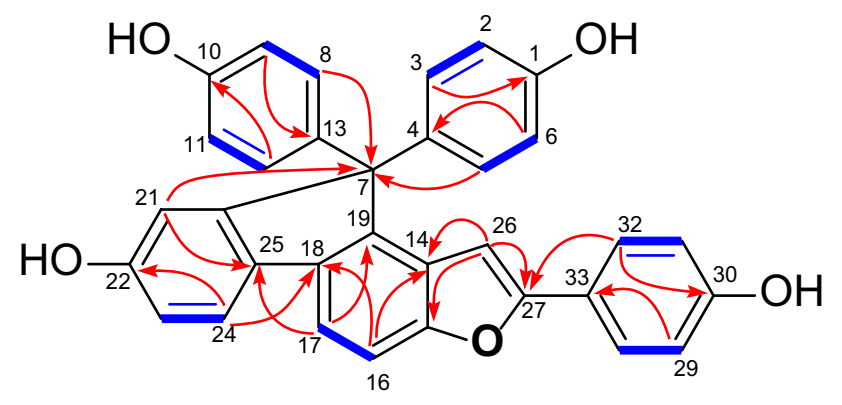

1

Fig. 2 Selected ${ }^{1} \mathrm{H}^{-1} \mathrm{H}$ COSY $(\longrightarrow)$ and $\operatorname{HMBC}(\longrightarrow)$ correlations of 1

rings were located at $\mathrm{C}-7$, as demonstrated by $\mathrm{HMBC}$ correlations of $\mathrm{H}-3, \mathrm{H}-5, \mathrm{H}-8$, and $\mathrm{H}-12$ with $\mathrm{C}-7$. The HMBC correlations from $\mathrm{H}-17$ to C-25 $\left(\delta_{\mathrm{C}} 133.1\right)$ and from $\mathrm{H}-24$ to $\mathrm{C}-18\left(\delta_{\mathrm{C}} 135.8\right)$ suggested two multisubstituted benzene rings was linked via C-18/C-25 bond. In addition, ring $\mathrm{E}$ was further linked to $\mathrm{C}-7$ on the basis of the HMBC correlation from $\mathrm{H}-21$ to $\mathrm{C}-7$ of the fluorene. Further observation of the cross-peaks between the olefinic proton $\mathrm{H}-26$ and C-14 $\left(\delta_{\mathrm{C}} 127.3\right), \mathrm{C}-15\left(\delta_{\mathrm{C}} 155.3\right)$, and $\mathrm{C}-27\left(\delta_{\mathrm{C}} 157.1\right)$ placed a styryl group at $\mathrm{C}-14$. Moreover, the 4-hydroxylphenyl group was linked to C-27 by HMBC correlations of $\mathrm{H}-28$ and $\mathrm{H}-32$ with C-27. Due to the five phenyl rings, a fluorene core, a double bond only expended 22 of the 23 degrees of unsaturation, the remaining unsaturation unit required that $\mathbf{1}$ had one more ring than that of selaginpulvilin, and the severely downfield-shifted $s p^{2}$ carbon at C-27 led to the construction of a furan ring between $\mathrm{C}-15$ and $\mathrm{C}-27$. On the basis of the above evidence, the gross structure of $\mathbf{1}$ with a 2-(4-hydroxyphenyl)-benzofuran unit was proposed (Fig. 1), which was fully consistent with its molecular composition, and represented a new skeleton for the selaginpulvilins.

Isoselagintamarlin A represents a hitherto unknown selaginellin skeleton, based on the cooccurrence of compounds 2-5, a plausible biogenetic pathway for $\mathbf{1}$ was proposed (Scheme 1). Selaginpulvilin A (2), the major component, was considered as the precusor. In brief, $\mathbf{2}$ underwent sequential oxidation to form selaginpulvilin J. The key step in this proposal was that the hydroxy group at C-15 attacked the triple bond to form a stable furan ring of isoselagintamarlin A (1).

Since no direct HMBC correlations were available to the new ring, as well as the limited amount of $\mathbf{1}$, its single crystals could not be obtained. Taken together, the structure of $\mathbf{1}$ remains ambiguous. We thus decided to carry out a biomimetic semisynthesis of $\mathbf{1}$, which can not only unequivocally confirm the complete structure but also provide sufficient quantities for further bioactiviy studies.

As outlined in Scheme 2, selaginpulvilin A (2), the major component, was considered as the precusor of $\mathbf{1}$. Selaginpulvilin A (2) was first converted to its acetylated $\left(\mathrm{Ac}_{2} \mathrm{O}\right.$ without base in acetone) derivative (6), which then reacted with $\mathrm{MnO}_{2}$ at $40{ }^{\circ} \mathrm{C}$ for $24 \mathrm{~h}$ to generate aldehyde 7 . Next,

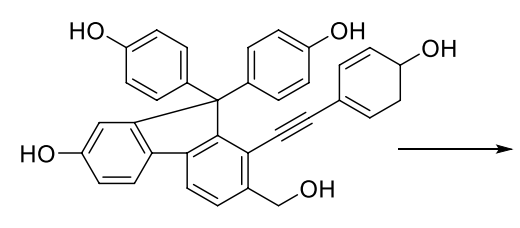

selaginpulvilin A

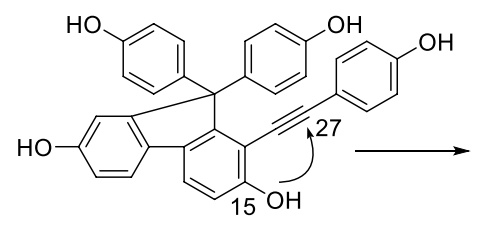

selaginpulvilin $\mathrm{J}$

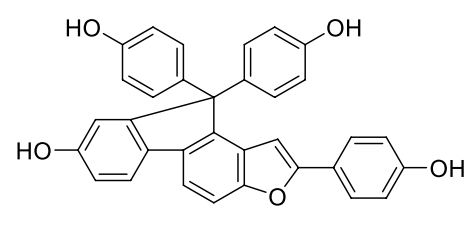

isoselagintamarlin $\mathrm{A}$

Scheme 1 Plausible biogenetic formation of 1
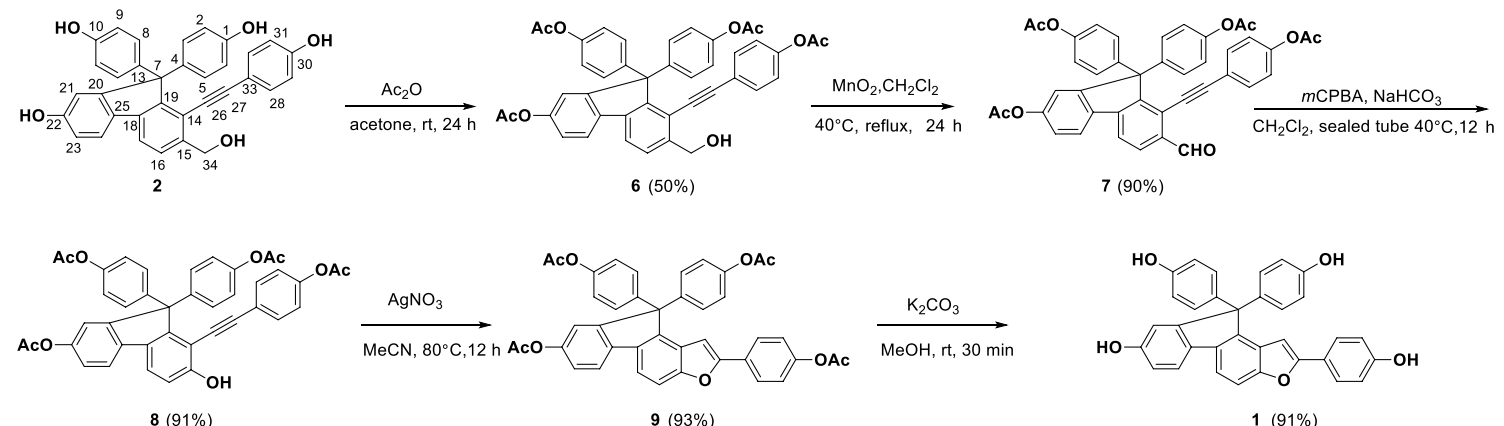

$9(93 \%)$

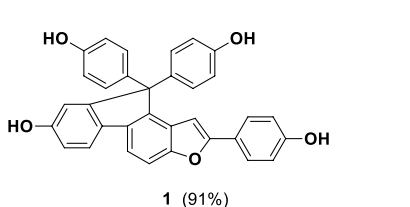

Scheme 2 Biomimetic semisynthesis structures of compound 1 
compound 7 was directly converted to phenol 8 under the condition of $m \mathrm{CPBA} / \mathrm{NaHCO}_{3}$ through the Baeyer-Villiger oxidation [14] reaction in $91 \%$ yield. According to the hypothetical biogenetic pathway of $\mathbf{1}$ (Scheme 1), compound $\mathbf{9}$ could be generated from a 5-exo-dig cyclization of $\mathbf{8}$ in the presence of catalytic $\mathrm{AgNO}_{3}$ in $93 \%$ yield. Finally, 9 was treated with $\mathrm{K}_{2} \mathrm{CO}_{3}$ to provide the target molecule 1 . The spectroscopic data $\left({ }^{1} \mathrm{H},{ }^{13} \mathrm{C}\right.$ NMR and HR-ESI-MS analysis) of the synthetic compound were identical to those of natural isoselagintamarlin A (1), which further secured the structure of $\mathbf{1}$. Furthermore, it was reported that the conversion of selaginpulvilin $\mathrm{A}$ to selaginpulvilins $\mathrm{B}, \mathrm{F}$ and $\mathrm{H}$ were unsuccessful by the reason that there was no oxidation of hydroxy group presented in trimethyl-selaginpulvilin A [9]. In the biomimetic semisynthesis tetraacetylated-selaginpulvilin $\mathrm{A}$ could be transformed into tetraacetylated-selaginpulvilin B, which provided an opportunity for the synthesis of other members of this family of natural products.

The known compounds were identified as selaginpulvilins A-D (2-5) by comparison of their spectroscopic and physical data with those in the literature [7].

\section{Experimental}

\subsection{General}

IR spectra were obtained on a Tenor 27 spectrometer with KBr pellets. ${ }^{1} \mathrm{H}$ and ${ }^{13} \mathrm{C}$ NMR spectra were performed on AVANCE III-600 and AV 800 spectrometers with TMS as an internal standard (Bruker, Karlsruhe, Germany). ESIMS were run on an Agilent 6540 Q-TOF spectrometer (Agilent, Palo Alto, CA, USA). HR-EI-MS were run on an Shimadzu UPLC-IT-TOF spectrometer. HR-ESI-MS were measured using Agilent G6230 TOF MS (Agilent, Palo Alto, CA, USA). Semi-preparative HPLC was performed on an Agilent 1260 apparatus equipped with a diode-array detector and a Zorbax SB-C18 (Agilent, $9.4 \mathrm{~mm} \times 25 \mathrm{~cm}$ ) column. Column chromatography (CC) was performed using MCI gel (CHP 20P, 75-150 mm; Mitsubishi Chemical Corporation, Tokyo, Japan), silica gel (100-200 or 200-300 mesh, Qingdao Marine Chemical Co. Ltd., Qingdao, China) and Sephadex LH-20 (Amersham Pharmacia Biotech, Sweden). Thin-layer chromatography (TLC) was carried out on silica gel $\mathrm{GF}_{254}$ on glass plates (Qingdao Marine Chemical Inc.) and spots were visualized by heating silica gel plates sprayed with $10 \% \mathrm{H}_{2} \mathrm{SO}_{4}$ in EtOH. All reactions sensitive to air or moisture were carried out under argon or nitrogen atmosphere in dry and freshly distilled solvents under anhydrous conditions, unless otherwise noted.

\subsection{Plant Material}

The entire plant of $S$. tamariscina used in this study was purchased from kunming Chinese herbal medicine professional market, Kunming, Yunnan Province, People's Republic of China in 2014 and identified by Prof. Xiao Cheng of the Kunming Institute of Botany, Chinese Academy of Sciences. A voucher specimen (No. 20140608P01) has been deposited at the state key Laboratory of Phytochemistry and Plant Resources in West China, Kunming Institute of Botany, Chinese Academy of Sciences, People's Republic of China.

\subsection{Extraction and Isolation}

The air-dried powder of the entire plants of Selaginella tamariscina $(11 \mathrm{~kg})$ was extracted three times with $70 \% \mathrm{EtOH}$ $(3 \times 35 \mathrm{~L})$ at room temperature for $72 \mathrm{~h}$, which was then concentrated in vacuo to give deposition portion $(450 \mathrm{~g})$. The deposition were chromatographed over a reversed-phase preparative MPLC (MCI) column eluting with a gradient mobile phase $\left(\mathrm{MeOH} / \mathrm{H}_{2} \mathrm{O}, 5 \% \rightarrow 95 \%, \mathrm{v} / \mathrm{v}\right)$ to give five fractions A-E. Fraction $\mathrm{C}(60 \mathrm{~g})$ was chromatographed over a silica gel column $\left(\mathrm{CHCl}_{3} / \mathrm{MeOH}, 100: 1-0: 1\right)$ to get five fractions (I-V), based on their TLC characteristics. Fraction III (19 g) was further separated by silica gel column eluted with $\mathrm{CHCl}_{3} / \mathrm{MeOH}(20: 1 \rightarrow 0: 1, \mathrm{v} / \mathrm{v})$ to give five fractions (III-A to III-E). Fraction III-D (2.5 g) was further separated by Sephadex LH-20 column $(\mathrm{MeOH})$ and then purified by semi-preparative HPLC using $35 \% \mathrm{MeCN} / \mathrm{H}_{2} \mathrm{O}$ (flow rate $=5 \mathrm{~mL} \mathrm{~min}^{-1}$ ) to afford $2\left(380 \mathrm{mg}, t_{\mathrm{R}}=24.7 \mathrm{~min}\right.$ ) and $5\left(65 \mathrm{mg}, t_{\mathrm{R}}=28.3 \mathrm{~min}\right)$, respectively. Fraction III-C (1.8 g) was subjected to silica gel column chromatography (petroleum ether/acetone, 6:4, v/v) to give two subfractions (III-Ca to III-Cb). Fraction III-Ca $(210 \mathrm{mg}$ ) was separated by semi-preparative HPLC $\left(32 \% \mathrm{MeCN} / \mathrm{H}_{2} \mathrm{O}\right.$, flow rate $\left.=5 \mathrm{~mL} \mathrm{~min}^{-1}\right)$ to yield compound $1(1.6 \mathrm{mg}$, $\left.t_{\mathrm{R}}=27.5 \mathrm{~min}\right)$. Fraction III-Cb $(480 \mathrm{mg})$ was isolated repeatedly by Sephadex LH-20 gel column $(\mathrm{MeOH})$ and then separated by semi-preparative HPLC $\left(42 \% \mathrm{MeCN} / \mathrm{H}_{2} \mathrm{O}\right.$, flow rate $\left.=5 \mathrm{~mL} \mathrm{~min}^{-1}\right)$ to obtain $3\left(8 \mathrm{mg}, t_{\mathrm{R}}=14.1 \mathrm{~min}\right)$ and 4 $\left(18 \mathrm{mg}, t_{\mathrm{R}}=17.5 \mathrm{~min}\right)$.

\subsubsection{Isoselagintamarlin A (1)}

Yellow oil; IR (KBr) $v_{\max } 3427,1612,1507,1427$ and $794 \mathrm{~cm}^{-1}$. UV (MeOH) $\lambda_{\max }(\log \varepsilon) 314$ (4.34), 284 (4.25), 204 (4.25). ${ }^{1} \mathrm{H}-\mathrm{NMR}$ ( $800 \mathrm{MHz}$, acetone- $d_{6}$ ) and ${ }^{13} \mathrm{C}-$ NMR (200 MHz, acetone- $d_{6}$ ), see Table 1 . HR-EI-MS $\mathrm{m} / \mathrm{z}$ $498.1454[\mathrm{M}]^{+}$(calcd for $\left.\mathrm{C}_{33} \mathrm{H}_{22} \mathrm{O}_{5}, 498.1467\right)$. 


\subsection{Semisynthesis and Characterization}

Tetraacetylated-selaginpulvilin A (6). A sample of acetic anhydride (274.5 $u \mathrm{~L})$ was added to a solution of $2(248 \mathrm{mg})$ in dry acetone $(15 \mathrm{~mL})$, and the mixture was stirred at $\mathrm{rt}$ until the starting material was consumed (TLC analysis). After solvent removing, the residue was purified by flash column chromatography on silica gel (petroleum ether/ acetone $=2: 1, \mathrm{v} / \mathrm{v}$ ) to give acetylation product $\mathbf{6}$ as a yellow oil $(163 \mathrm{mg}, 50 \%$ yield $) .{ }^{1} \mathrm{H}-\mathrm{NMR}\left(\mathrm{CDCl}_{3}, 600 \mathrm{MHz}\right)$ $\delta_{\mathrm{H}} 7.75(1 \mathrm{H}, \mathrm{d}, J=8.0 \mathrm{~Hz}), 7.74(1 \mathrm{H}, \mathrm{d}, J=8.0 \mathrm{~Hz}), 7.55$ $(1 \mathrm{H}, \mathrm{d}, J=8.0 \mathrm{~Hz}), 7.29(4 \mathrm{H}, \mathrm{d}, J=8.7 \mathrm{~Hz}), 7.14(1 \mathrm{H}, \mathrm{d}$, $J=8.0 \mathrm{~Hz}), 7.04(2 \mathrm{H}, \mathrm{d}, J=8.5 \mathrm{~Hz}), 7.02(1 \mathrm{H}, \mathrm{s}), 7.01(2 \mathrm{H}$, d, $J=8.5 \mathrm{~Hz}), 6.90(4 \mathrm{H}, \mathrm{d}, J=8.7 \mathrm{~Hz}), 4.87(2 \mathrm{H}, \mathrm{s}), 2.30$ $(3 \mathrm{H}, \mathrm{s}), 2.25(9 \mathrm{H}, \mathrm{s}) ;{ }^{13} \mathrm{C}-\mathrm{NMR}\left(\mathrm{CDCl}_{3}, 150 \mathrm{MHz}\right) \delta_{\mathrm{C}} 169.3$ (s), $169.1(\mathrm{~s}), 154.0(\mathrm{~s}), 152.0(\mathrm{~s}), 150.9(\mathrm{~s}), 150.8(\mathrm{~s}), 149.5$ (s), $142.5(\mathrm{~s}), 139.5(\mathrm{~s}), 139.1$ (s), 136.5 (s), 132.5 (d), 130.0 (d), 127.4 (d), 122.0 (d), 121.4 (d), 121.0 (d), 120.5 (d), 120.3 (d), 120.1 (s), 119.1 (s), 119.0 (d), 101.0 (s), 85.5 (s), 65.4 (s), 63.9 (t), 21.1 (q); HR-ESI-MS m/z: 703.1941 $[\mathrm{M}+\mathrm{Na}]^{+}$(calc. for $\mathrm{C}_{42} \mathrm{H}_{32} \mathrm{O}_{9} \mathrm{Na}, 703.1939$ ).

Tetraacetylated-selaginpulvilin B (7). Compound 6 (150 mg), activated $\mathrm{MnO}_{2}(191.9 \mathrm{mg})$ and DCM (25 mL) were placed in a $75 \mathrm{~mL}$ thick walled glass pressure tube. The tube was sealed and the solution was stirred at $40{ }^{\circ} \mathrm{C}$ for $24 \mathrm{~h}$. After cooling to room temperature, the mixture was filtered, evaporated under vacuum, and the residue was purified by flash column chromatography on silica gel (petroleum ether/acetone $=4: 1, \mathrm{v} / \mathrm{v}$ ) to give aldehyde 7 as a yellow oil (135 mg, 90\% yield). ${ }^{1} \mathrm{H}-\mathrm{NMR}\left(\mathrm{CDCl}_{3}, 600 \mathrm{MHz}\right) \delta_{\mathrm{H}} 10.5$ $(1 \mathrm{H}, s), 8.03(1 \mathrm{H}, \mathrm{d}, J=8.0 \mathrm{~Hz}), 7.82(1 \mathrm{H}, \mathrm{d}, J=8.0 \mathrm{~Hz})$, $7.81(1 \mathrm{H}, \mathrm{d}, J=8.0 \mathrm{~Hz}), 7.28(4 \mathrm{H}, \mathrm{d}, J=8.8 \mathrm{~Hz}), 7.18(1 \mathrm{H}$, $\mathrm{dd}, J=8.0,2.0 \mathrm{~Hz}), 7.06(1 \mathrm{H}, \mathrm{br} \mathrm{s}), 7.05(2 \mathrm{H}, \mathrm{d}, J=8.7 \mathrm{~Hz})$, $7.02(2 \mathrm{H}, \mathrm{d}, J=8.7 \mathrm{~Hz}), 6.94(4 \mathrm{H}, \mathrm{d}, J=8.7 \mathrm{~Hz}), 2.28(3 \mathrm{H}$, s), $2.24(9 \mathrm{H}, \mathrm{s}) ;{ }^{13} \mathrm{C}-\mathrm{NMR}\left(\mathrm{CDCl}_{3}, 150 \mathrm{MHz}\right) \delta_{\mathrm{C}} 191.2(\mathrm{~d})$, $169.3(\mathrm{~s}), 169.0(\mathrm{~s}), 155.4(\mathrm{~s}), 152.4(\mathrm{~s}), 152.0(\mathrm{~s}), 151.2(\mathrm{~s})$, $149.8(\mathrm{~s}), 145.5(\mathrm{~s}), 138.2(\mathrm{~s}), 135.4(\mathrm{~s}), 135.3(\mathrm{~s}), 132.6(\mathrm{~d})$, 129.9 (d), 128.1 (d), 124.3 (d), 122.1 (d), 121.9 (d), 121.7 (d), 121.1 (d), 120.2 (s), 119.4 (s), 119.2 (d), 103.4 (s), 83.7 (s), 65.4 (s), 21.1 (q); HR-ESI-MS m/z: $701.1780[\mathrm{M}+\mathrm{Na}]^{+}$ (calc. for $\mathrm{C}_{42} \mathrm{H}_{30} \mathrm{O}_{9} \mathrm{Na}, 701.1782$ ).

Tetraacetylated-selaginpulvilin $\mathbf{J}(\mathbf{8})$. To a stirred solution of $7(100 \mathrm{mg})$ in dry DCM $(15 \mathrm{~mL}), \mathrm{NaHCO}_{3}$ (24.8 $\mathrm{mg}$ ) and $m$ CPBA (38.2 $\mathrm{mg}$ ) was added. The mixture was sealed and stirred at $40{ }^{\circ} \mathrm{C}$ for $12 \mathrm{~h}$, then washed with saturated $\mathrm{NaHCO}_{3}$ solution for three times. After removal of solvents, the residue was purified by flash column chromatography on silica gel (petroleum ether/acetone $=4: 1$, $\mathrm{v} / \mathrm{v})$ to give phenol 8 as a yellow oil $(89 \mathrm{mg}, 91 \%$ yield). ${ }^{1} \mathrm{H}-\mathrm{NMR}\left(\mathrm{CDCl}_{3}, 600 \mathrm{MHz}\right) \delta_{\mathrm{H}} 7.64(1 \mathrm{H}, \mathrm{d}, J=8.3 \mathrm{~Hz})$, $7.61(1 \mathrm{H}, \mathrm{d}, J=8.3 \mathrm{~Hz}), 7.26(4 \mathrm{H}, \mathrm{d}, J=8.8 \mathrm{~Hz}), 7.09(2 \mathrm{H}$, d, $J=8.6 \mathrm{~Hz}), 7.08-7.10(1 \mathrm{H}, \mathrm{m}), 7.04(2 \mathrm{H}, \mathrm{d}, J=8.6 \mathrm{~Hz})$,
$7.02(1 \mathrm{H}, \mathrm{d}, J=8.3 \mathrm{~Hz}), 6.98(1 \mathrm{H}, \mathrm{d}, J=2.0 \mathrm{~Hz}), 6.90(4 \mathrm{H}$, $\mathrm{d}, J=8.8 \mathrm{~Hz}), 2.28(3 \mathrm{H}, \mathrm{s}), 2.24(6 \mathrm{H}, \mathrm{s}), 2.22(3 \mathrm{H}, \mathrm{s}) ;{ }^{13} \mathrm{C}-$ $\operatorname{NMR}\left(\mathrm{CDCl}_{3}, 150 \mathrm{MHz}\right) \delta_{\mathrm{C}} 169.4(\mathrm{~s}), 169.3(\mathrm{~s}), 169.1(\mathrm{~s})$, $156.8(\mathrm{~s}), 153.1(\mathrm{~s}), 152.3(\mathrm{~s}), 151.0(\mathrm{~s}), 150.0(\mathrm{~s}), 149.6$ (s), 139.3 (s), 137.0 (s), 132.6 (d), 132.5 (s), 130.0 (d), 122.0 (d), 121.9 (d), 121.3 (d), 121.0 (d), 119.6 (d), 119.5 (s), 118.9 (d), 114.5 (d), 107.8 (s), 102.4 (s), 81.7 (s), 65.2 (s), 21.1 (q); HR-ESI-MS m/z: $705.1524[\mathrm{M}+\mathrm{K}]^{+}$(calc. for $\mathrm{C}_{41} \mathrm{H}_{30} \mathrm{O}_{9} \mathrm{~K}, 705.1521$ ).

Tetraacetylated-isoselagintamarlin A (9). To a stirred solution of $8(76 \mathrm{mg})$ in $\mathrm{MeCN}(15 \mathrm{~mL}), \mathrm{AgNO}_{3}(9.7 \mathrm{mg})$ was added. The mixture was stirred at $80{ }^{\circ} \mathrm{C}$ for $12 \mathrm{~h}$ and the solvent was evaporated under vacuum. The residue was diluted with $\mathrm{H}_{2} \mathrm{O}$ and extracted with EtOAc $(10 \mathrm{~mL} \times 3)$, dried over $\mathrm{Na}_{2} \mathrm{SO}_{4}$. The solvent was evaporated under vacuum and the residue was purified by flash column chromatography on silica gel (petroleum ether/acetone $=5: 1$, $\mathrm{v} / \mathrm{v})$ to afford compound 9 as a yellow oil $(71 \mathrm{mg}, 93 \%$ yield). ${ }^{1} \mathrm{H}-\mathrm{NMR}$ (aceton- $\left.d_{6}, 600 \mathrm{MHz}\right) \delta_{\mathrm{H}} 7.93(2 \mathrm{H}, \mathrm{d}$, $J=8.6 \mathrm{~Hz}), 7.91-7.93(1 \mathrm{H}, \mathrm{m}), 7.90(1 \mathrm{H}, \mathrm{d}, J=8.4 \mathrm{~Hz})$, $7.67(1 \mathrm{H}, \mathrm{d}, J=8.4 \mathrm{~Hz}), 7.32(4 \mathrm{H}, \mathrm{d}, J=8.8 \mathrm{~Hz}), 7.28(1 \mathrm{H}$, $\mathrm{d}, J=2.0 \mathrm{~Hz}), 7.23(1 \mathrm{H}, \mathrm{s}), 7.21(2 \mathrm{H}, \mathrm{d}, J=8.6 \mathrm{~Hz}), 7.18$ $(1 \mathrm{H}, \mathrm{dd}, J=8.2,2.0 \mathrm{~Hz}), 7.04(4 \mathrm{H}, \mathrm{d}, J=8.8 \mathrm{~Hz}), 2.26$ $(3 \mathrm{H}, \mathrm{s}), 2.21(3 \mathrm{H}, \mathrm{s}), 2.20(6 \mathrm{H}, \mathrm{s}) ;{ }^{13} \mathrm{C}-\mathrm{NMR}$ (aceton- $d_{6}$, $150 \mathrm{MHz}) \delta_{\mathrm{C}} 169.7(\mathrm{~s}), 169.5(\mathrm{~s}), 169.5(\mathrm{~s}), 157.0(\mathrm{~s})$, $156.3(\mathrm{~s}), 154.1$ (s), $152.4(\mathrm{~s}), 151.4(\mathrm{~s}), 151.0(\mathrm{~s}), 144.0$ (s), $141.8(\mathrm{~s}), 138.8(\mathrm{~s}), 135.1(\mathrm{~s}), 130.2(\mathrm{~d}), 128.3(\mathrm{~s})$, $127.1(\mathrm{~s}), 127.0(\mathrm{~d}), 123.2(\mathrm{~d}), 122.5(\mathrm{~d}), 122.5(\mathrm{~d}), 121.1$ (d), 120.1 (d), 117.7 (d), 112.0 (d), 101.1 (d), 67.3 (s), 20.9 (q); HR-ESI-MS m/z: $705.1531[\mathrm{M}+\mathrm{Na}]^{+}$(calc. for $\left.\mathrm{C}_{41} \mathrm{H}_{30} \mathrm{O}_{9} \mathrm{Na}, 705.1521\right)$.

Isoselagintamarlin A (1) prepared from biomimetic semisynthesis. The mixture of $\mathbf{9}(56 \mathrm{mg})$ and $\mathrm{K}_{2} \mathrm{CO}_{3}$ $(69.7 \mathrm{mg})$ in $\mathrm{MeOH}(15 \mathrm{~mL})$ was stirred at room temperature for $30 \mathrm{~min}$, and the solvent was evaporated under vacuum. The residue was diluted with $\mathrm{H}_{2} \mathrm{O}$ and extracted with EtOAc $(10 \mathrm{~mL} \times 3)$, dried over $\mathrm{Na}_{2} \mathrm{SO}_{4}$. The solvent was evaporated under vacuum and the residue was purified by flash column chromatography on silica gel (petroleum ether/acetone $=2: 1, \mathrm{v} / \mathrm{v}$ ) to afford $\mathbf{1}$ as a yellow oil (38 mg, 91\% yield). The NMR data of this synthetic compound are consistent with those of this compound isolated from plants, see Table 1; HR-ESI-MS m/z: 497.1380 [M $-\mathrm{H}^{-}{ }^{-}$(calc. 497.1394).

Acknowledgements This work was financially supported by the NSFCJoint Foundation of Yunnan Province (No. U1502223), the National Natural Science Foundation of China (Nos. 21837003, 21778059 and 81773611), the Science and Technology Program of Yunnan Province (No. 2018ZF001).

\section{Compliance with Ethical Standards}

Conflict of interest The authors declare no conflict of interest. 
Open Access This article is distributed under the terms of the Creative Commons Attribution 4.0 International License (http://creativeco mmons.org/licenses/by/4.0/), which permits unrestricted use, distribution, and reproduction in any medium, provided you give appropriate credit to the original author(s) and the source, provide a link to the Creative Commons license, and indicate if changes were made.

\section{References}

1. L.P. Zhang, Y.M. Liang, X.C. Wei, D.L. Cheng, J. Org. Chem. 72, 3921-3924 (2007)

2. X.L. Cheng, S.C. Ma, J.D. Yu, S.Y. Yang, X.Y. Xiao, J.Y. Hu, Y. Lu, P.C. Shaw, P.P.H. But, R.C. Lin, Chem. Pharm. Bull. 56, 982-984 (2008)

3. G.S. Tan, K.P. Xu, F.S. Li, C.J. Wang, T.Y. Li, C.P. Hu, J. Shen, Y.J. Zhou, Y.J. Li, J. Asian Nat. Prod. Res. 11, 1001-1004 (2009)

4. Y. Cao, J.J. Chen, N.H. Tan, L. Oberer, T. Wagner, Y.P. Wu, G.Z. Zeng, H. Yan, Q. Wang, Bioorg. Med. Chem. Lett. 20, 2456-2460 (2010)
5. C.J. Wang, C.P. Hu, K.P. Xu, Q. Yuan, F.S. Li, H. Zou, G.S. Tan, Y.J. Li, Naunyn-Schmiedeberg's Arch. Pharmacol. 381, 73-81 (2010)

6. C. Yang, Y. Shao, K. Li, W. Xia, Beilstein J. Org. Chem. 8, 1884 $1889(2012)$

7. X. Liu, H.B. Luo, Y.Y. Huang, J.M. Bao, G.H. Tang, Y.Y. Chen, J. Wang, S. Yin, Org. Lett. 16, 282-285 (2014)

8. P.H. Nguyen, B.T. Zhao, M.Y. Ali, J.S. Choi, D.Y. Rhyu, B.S. Min, M.H. Woo, J. Nat. Prod. 78, 34-42 (2015)

9. B.S. Chinta, B. Baire, Org. Biomol. Chem. 15, 5908-5911 (2017)

10. M.J. Sowden, M.S. Sherburn, Org. Lett. 19, 636-637 (2017)

11. B.S. Chinta, B. Baire, Org. Biomol. Chem. 16, 262-265 (2018)

12. Chinese Pharmacopoeia Commission, Pharmacopoeia of the People's Republic of China. 1, 226 (2015)

13. Q.F. Zhu, Y. Bao, Z.J. Zhang, J. Su, L.D. Shao, Q.S. Zhao, R. Soc, Open Sci. 4, 170352 (2017)

14. G.R. Krow, Tetrahedron 37, 2697-26724 (1981) 